\title{
Evidence that single nucleotide polymorphism in the uncoupling protein 3 (UCP3) gene influences fat distribution in women of European and Asian origin
}

\author{
P. G. Cassell ${ }^{1}$, P.J.Saker ${ }^{2}$, S.J.Huxtable ${ }^{2}$, E. Kousta ${ }^{2}$, A.E.Jackson ${ }^{1}$, A.T. Hattersley ${ }^{3}$, T.M. Frayling ${ }^{3}$, M. Walker ${ }^{4}$, \\ P. G. Kopelman ${ }^{1}$, A. Ramachandran ${ }^{5}$, C.Snehelatha ${ }^{5}$, G. A.Hitman ${ }^{1}$, M. I. McCarthy ${ }^{2}$ \\ ${ }^{1}$ Department of Diabetes and Metabolic Medicine, St Bartholomews and the Royal London School of Medicine and Dentistry, \\ Queen Mary and Westfield College, London, UK \\ ${ }^{2}$ Division of Medicine, Imperial College Genetics and Genomics Research Institute and MRC Clinical Sciences Centre, Imperial \\ College School of Medicine, London, UK \\ ${ }^{3}$ Department of Diabetes and Vascular Medicine, School of Postgraduate Medicine and Health Sciences, University of Exeter, \\ Exeter, UK \\ ${ }^{4}$ Department of Medicine, School of Medicine, Newcastle-upon-Tyne, UK \\ ${ }^{5}$ Diabetes Research Centre, Chennai, India
}

\section{Abstract}

Aims/hypothesis. Uncoupling proteins are mitochondrial transmembrane carriers implicated in the regulation of energy balance. Dysfunction of UCP3 (the predominant uncoupling protein in skeletal muscle) might therefore be expected to reduce thermogenic capacity, alter energy homeostasis and influence predisposition to obesity and Type II (non-insulin-dependent) diabetes mellitus. A variant in the putative promoter region of $U C P 3(-55 \mathrm{c} \rightarrow \mathrm{t})$ has recently been identified, and an association with obesity reported in French subjects. Our aim was to study the pathophysiological role of this variant in diabetes-related and obesity-related traits using two distinct ethnic populations.

Methods. The $-55 \mathrm{c} \rightarrow \mathrm{t}$ variant was genotyped in 85 South Indian and 150 European parent-offspring trios ascertained through Type II diabetic probands and in 455 South Indian subjects initially recruited to an urban survey into the prevalence of diabetes.

Results. In South Indian and European parent-offspring trios there was no preferential transmission of either allele at the $-55 \mathrm{c} \rightarrow \mathrm{t}$ polymorphism to diabetic offspring (South Indians, $p=0.60$; Europeans, $p=0.15)$. When family members were analysed for intermediate traits, the t-allele was associated with increased waist-to-hip ratio but only in females (South Indian mothers $p=0.036$, daughters $p=0.032$ : European mothers $p=0.037$, daughters $p=0.14)$. These findings were replicated in South Indian females from the population-based survey $(p=0.039)$.

Conclusion/interpretation. The consistent association between the t-allele at this locus and increased waist-to-hip ratio in women from three separate data sets indicates that variation at this polymorphism (or another locus with which it is in linkage disequilibrium) influences fat distribution but that this effect is restricted to females. [Diabetologia (2000) 43: 15581564]

Keywords Uncoupling protein-3, Europeans, South Indians, family association, fat distribution, body mass index, Type II diabetes.
Received: 8 June 2000 and in final revised form: 6 September 2000

Corresponding author: M. McCarthy, Professor of Genomic Medicine, Dept of Metabolic Medicine, Imperial College School of Medicine (St Mary's Hospital), Norfolk Place, London W2 1PG, UK

Abbreviations: UCP, Uncoupling protein; RFLP, restriction fragment length polymorphism; WHR, waist-to-hip ratio; SNP, single nucleotide polymorphism; TDT, transmission disequilibrium test; QTDT, quantitative trait transmission disequilibrium test; MODY, maturity onset diabetes of the young; indel, insertion-deletion; UTR, untranslated region.
The rising prevalence of Type II (non-insulin-dependent) diabetes and obesity worldwide poses a serious challenge to human health and incomplete understanding of the aetiological basis of these closely related metabolic conditions is a major impediment to improved management. There is considerable evidence to suggest that primary abnormalities in energy balance contribute to the pathogenesis of diabetes and obesity [1]. Reduced energy expenditure is correlated with subsequent weight gain [2] and normoglycaemic women at increased risk of future diabetes have defective post-prandial thermogenesis [3, 4]. 
Table 1. Demographic and anthropometric details in the main study groups

\begin{tabular}{|c|c|c|c|c|c|c|}
\hline & \multicolumn{2}{|c|}{$\begin{array}{l}\text { South Indian Type II diabetic } \\
\text { parent-offspring trios }\end{array}$} & \multicolumn{2}{|c|}{ South Indian urban cohort } & \multicolumn{2}{|c|}{$\begin{array}{l}\text { European Type II diabetic } \\
\text { parent-offspring trios }\end{array}$} \\
\hline & $\begin{array}{l}\text { Male } \\
\text { probands }\end{array}$ & $\begin{array}{l}\text { Female } \\
\text { probands }\end{array}$ & Men & Women & $\begin{array}{l}\text { Male } \\
\text { probands }\end{array}$ & $\begin{array}{l}\text { Female } \\
\text { probands }\end{array}$ \\
\hline Number & 54 & 31 & 235 & 220 & 92 & 58 \\
\hline Age at diagnosis (years) & $34(29-38)$ & $32(25-37)$ & $47(40-55)^{\mathrm{a}}$ & $42(34-53)^{\mathrm{a}}$ & $41(25-58)$ & $39(25-55)$ \\
\hline $\begin{array}{l}\text { Treatment: } \\
\text { Diet only } n(\%) \\
\text { Oral agents } n(\%) \\
\text { Insulin } n(\%)\end{array}$ & $\begin{array}{c}4(7 \%) \\
46(85 \%) \\
4(7 \%)\end{array}$ & $\begin{array}{c}2(6 \%) \\
22(71 \%) \\
7(23 \%)\end{array}$ & $\begin{array}{l}- \\
- \\
-\end{array}$ & $\begin{array}{l}- \\
- \\
-\end{array}$ & $\begin{array}{l}16(18 \%) \\
61(66 \%) \\
15(16 \%)\end{array}$ & $\begin{array}{r}15(26 \%) \\
35(60 \%) \\
8(14 \%)\end{array}$ \\
\hline $\operatorname{BMI}\left(\mathrm{kg} / \mathrm{m}^{2}\right)$ & $26.2(22.4-30.7)$ & $26.4(22.0-31.5)$ & $21.8(18.4-25.8)$ & $22.7(18.6-27.6)$ & $30.5(25.6-36.3)$ & $32.9(25.8-41.9)$ \\
\hline Waist-to-hip ratio & $0.94(0.05)$ & $0.86(0.07)$ & $0.91(0.06)$ & $0.85(0.06)$ & $0.97(0.06)$ & $0.90(0.09)$ \\
\hline
\end{tabular}

Age at diagnosis is given as medians (range), BMI as geometric means (SD range), and WHR as means (SD). ${ }^{a}$ in the urban survey, this refers to the age at study

Recent identification of a family of uncoupling proteins [5-8] provides an opportunity to test this hypothesis directly, through detection of correlations between variation in the genes encoding these proteins and traits relevant to the development of diabetes and obesity.

Uncoupling proteins facilitate the dissipation of the electrochemical proton gradient established across the mitochondrial membrane, thereby uncoupling oxidative phosphorylation from ATP generation and allowing stored chemical energy to be converted to heat. In rodents, experimental modification of the expression of the Ucpl gene, which is expressed exclusively in brown adipose tissue, influences susceptibility to obesity $[9,10]$. Of the three proteins with putative uncoupling function identified in humans, uncoupling protein (UCP) 3 provides the strongest candidate for a role in the regulation of thermogenesis $[6,8]$. Uncoupling protein 3 shows uncoupling activity in certain expression systems [11-13] and is expressed predominantly in human skeletal muscle $[6,8]$, quantitatively the major site for energy expenditure $[1,14]$. Furthermore, UCP3 (with its close neighbour, $U C P 2$ ) maps to a region of chromosome 11q13 linked to resting metabolic rate and fat mass in French Canadians [15] and to post-glucose load insulin concentrations in Pima Indians [16]. The murine and rat homologues of these genes lie within regions implicated in several models of rodent obesity [17-21]. Finally, several groups have found that $U C P 3$ expression in skeletal muscle correlates with energy expenditure [22] and is altered in obesity or Type II diabetes [23, 24].

The search for genomic variants within the $U C P 3$ gene has, thus far, identified multiple polymorphisms including five intronic variants; seven silent coding variants; one premature stop codon; one variant in a splice donor site; four variants in 5' sequence; and five variants, all uncommon, altering the amino-acid sequence [25-31]. The strongest evidence for a phenotypic effect of any of these polymorphisms has been obtained for the exon 6 splice donor variant, associated with reduced fat oxidation and obesity in an African cohort [29]. Recently, we reported the identification, in a small number of South Indian and British Caucasoid subjects, of a $\mathrm{c} \rightarrow \mathrm{t}$ polymorphism at nucleotide position -55 within the putative core promoter [6, 7] of UCP3 [30] (equivalent to position 2933 of GenBank sequence AF032871). Subsequent studies in French obese cohorts showed that homozygosity for the t-allele at this site is associated with increased BMI [31] and could explain the previous report of a weak association between the exon 3 Tyr99Tyr variant and obesity [26]. Our aim in this study was to examine the relation between variation at the -55 $\mathrm{c} \rightarrow \mathrm{t}$ polymorphism and susceptibility to diabetes, obesity and related anthropometric traits in subjects from well-characterised populations from Europe and South Asia.

\section{Subjects and methods}

South Indian parent-offspring trios. South Indian parent-offspring trios ( $n=85$, all Dravidian) were ascertained in Chennai, India through Type II (non-insulin-dependent) diabetic offspring, as described previously [30, 32]. Clinical details of probands are provided in Table 1 . The mean (SD) age of fathers was 64.6 (6.8) years, with BMI [geometric mean (SD range)] of $24.0(20.8-27.7) \mathrm{kg} / \mathrm{m}^{2}$ and waist-to-hip ratio of 0.95 (0.05); corresponding figures in mothers were 57.7 (6.5) years, $25.4(21.5-29.9) \mathrm{kg} / \mathrm{m}^{2}$ and $0.88(0.07)$. None of the probands carried the mt3243 mutation [33].

South Indian urban survey cohort. DNA samples were available from 455 South Indian subjects initially recruited to a population-based survey of diabetes prevalence [34]. Of these, 333 $(73.2 \%)$ had normal glucose tolerance, 44 (9.7\%) impaired glucose tolerance and $78(17.1 \%)$ diabetes. Clinical characteristics are given in Table 1.

British Diabetic Association Warren 2 Trios collection. European parent-offspring trios $(n=150)$ were ascertained through probands with a clinical diagnosis of Type II diabetes and two living parents [35]. The principal ascertainment criteria were: 
(1) probands with a diagnosis of Type II diabetes after age 25;

(2) four grandparents of European origin; (3) exclusion of Type I (insulin-dependent) diabetes, maturity-onset diabetes of the young (MODY) and mitochondrial diabetes by personal and family history, GAD-antibody measurements and genetic screens for MODY and the mt3243 mutation [35]. Clinical details on probands are given in Table 1. Fathers' mean (SD) age at study was $73.7(7.4)$ years, BMI $26.9(23.3-31.1) \mathrm{kg} / \mathrm{m}^{2}$ and WHR 0.97 (0.07): corresponding figures in mothers were 72.2 (7.7) years, $27.5(23.1-32.7) \mathrm{kg} / \mathrm{m}^{2}$ and $0.87(0.08)$. Although ascertained solely for Type II diabetes, trios probands were considerably obese, suggesting that the early age of diagnosis of diabetes in these families reflects loading for both diabetes and obesity genes.

Informed consent was obtained from all subjects for extraction of genomic DNA and subsequent genetic analyses.

Genotyping. The $-55 \mathrm{c} \rightarrow \mathrm{t}$ polymorphism was genotyped using a restriction-generating restriction fragment length polymorphism (RFLP) assay. Standard PCR amplification used primers 5'-GGATAAGGTTTCAGGTCAGGC-3' and 5'-AAGGGATGAGGGAGGAGAAA-3'. Digestion of the 194bp product with HaeIII generated fragments of $110 \mathrm{bp}, 64 \mathrm{bp}$ and $20 \mathrm{bp}$ (c-allele) and/or 110bp and 84bp (t-allele) which were resolved on a $3 \%$ agarose gel stained with ethidium bromide. The UCP2 exon 8 insertion-deletion polymorphism was typed as reported previously [30].

Statistical methods. Evidence for association between variant genotypes and diabetes was sought using the transmission disequilibrium test (TDT) as implemented with the ETDT program [36] in the trios, and standard contingency table analyses in the urban cohort. The relations between genotypes and quantitative traits (weight, BMI, waist circumference, WHR, age at diagnosis of diabetes) in cross-sectional data sets were examined by analysis of variance in SPSS for Windows, (version 8). If not normally distributed (age at diagnosis of diabetes, BMI, weight), data were transformed before analysis. Given the low proportion of $\mathrm{tt}$ homozygotes ( $<5 \%$ in all groups), these analyses pooled ct and tt genotypes. Quantitative TDT analyses were undertaken for BMI and WHR in the trios' resources using the QTDT5 method of Allison [37] as implemented in QTDT (www.well.ox.ac.uk/asthma/QTDT) [38]. In addition, we used the "total association" option in QTDT to implement a non-TDT association test which incorporates multiple members of the same pedigree, whilst allowing for shared polygenic and environmental variances.

In the European trios, linkage disequilibrium between $U C P 3$ and $U C P 2$ polymorphisms was calculated using the maximum likelihood haplotype frequency estimates generated by TRANSMIT (www.hgmp.mrc.ac.uk) [39], in both the full set of 600 founder chromosomes and the subset of 300 untransmitted ('control') chromosomes. In the South Indian population-based urban survey, linkage disequilibrium was calculated with the EH program [40]. Statistical significance was defined as $p$ less than 0.05 .

\section{Results}

Allele frequencies. The frequency of the t-allele was $18 \%$ in the South Indian urban survey, $21 \%$ in the South Indian trios and $24 \%$ in the European trios (parental chromosomes only). There was no departure from Hardy-Weinberg equilibrium in either
South Indian group; in the European trios, there was a modest deficiency of tt homozygotes compared with that expected under Hardy-Weinberg equilibrium $(p=0.04)$.

Association with diabetes. Using family-based association methods, there was no evidence of excess transmission of either allele from heterozygous parents to diabetic offspring in either trio collection. In 58 heterozygous South Indian parents, 31 transmitted the t-allele and 27 the c-allele $(p=0.60)$. In 126 heterozygous European parents, 55 transmitted the t-allele, and 71 the c-allele $(p=0.15)$. In the South Indian urban cohort, there was no association between -55 $\mathrm{c} \rightarrow \mathrm{t}$ genotype and glucose tolerance status $(p=0.80$ and 0.49 for genotypes and alleles, respectively).

Associations with quantitative traits. When family members within the South Indian trios were analysed for intermediate traits related to development of diabetes and obesity (BMI, WHR, waist circumference), the $-55 \mathrm{t}$-allele was noted to be associated with increased WHR in female family members (Table 2). There was no significant relation with BMI (Table 3) or age of diagnosis (data not presented). The genotype-associated difference in WHR reached significance in the mothers [WHR [mean (SD)]: cc 0.87 (0.07) compared with ct/tt $0.90(0.08), p=0.036\}$ and in female probands [cc $0.84(0.07) \mathrm{vs} \mathrm{ct/tt} 0.89(0.06)$, $p=0.032]$ but there were no such differences in fathers or male probands. Applying the "total association" method implemented by QTDT to all South Indian trios (irrespective of proband sex but including sex as covariate), the association between $-55 \mathrm{c} \rightarrow \mathrm{t}$ genotype and WHR was confirmed $(p=0.029)$. Using quantitative TDT (Allison's QTDT5) to assess transmission from heterozygous parents to all offspring, no statistically significant effects were seen for WHR. Somewhat surprisingly, given the absence of any genotype-related differences in means (Table 3), evidence for skewed transmission of the -55 $\mathrm{c} \rightarrow \mathrm{t}$ variant was seen for BMI $(p=0.028$ with sex as covariate), higher BMI being associated with transmission of the t-allele.

Given the multiple phenotypes and subject groups assessed in this analysis, replication was sought in additional data sets. In the South Indian urban cohort, the t-allele was again associated with a modest increase in WHR in the 220 female participants [Table 2: cc $0.84(0.06)$ vs ct/tt $0.86(0.07), p=0.039$ ]. There was no association with WHR in males (Table 2) and no association with BMI in either sex (Table 3).

In European families, the pattern was similar to that in South-Indian trios, with evidence for increased WHR in female t-allele carriers (Table 2). In mothers, this reached formal levels of significance on non-parametric analysis [cc: $0.86(0.07) \mathrm{vs} \mathrm{ct} / \mathrm{tt}$ 
Table 2. Results of analyses at the $U C P 3-55 \mathrm{c} \rightarrow \mathrm{t}$ polymorphism for waist-to-hip ratio in two South Indian and one European study group

\begin{tabular}{|c|c|c|c|c|}
\hline & \multirow[b]{2}{*}{$n$} & \multicolumn{2}{|c|}{$U C P 3-55 \mathrm{c} \rightarrow \mathrm{t}$ genotype } & \multirow{2}{*}{$\begin{array}{l}p \text { value for compari- } \\
\text { son of the two groups }\end{array}$} \\
\hline & & $\mathrm{cc}$ & $\mathrm{ct} / \mathrm{tt}$ & \\
\hline \multicolumn{5}{|l|}{ South Indian trios } \\
\hline Mothers & 85 & $0.87(0.07)$ & $0.90(0.08)$ & 0.036 \\
\hline Male probands & 54 & $0.93(0.04)$ & $0.95(0.05)$ & 0.10 \\
\hline Female probands & 31 & $0.84(0.07)$ & $0.89(0.06)$ & 0.032 \\
\hline Females & 220 & $0.84(0.06)$ & $0.86(0.07)$ & 0.039 \\
\hline \multicolumn{5}{|l|}{ European trios } \\
\hline Fathers & 150 & $0.97(0.07)$ & $0.97(0.08)$ & 0.69 \\
\hline Mothers & 150 & $0.86(0.07)$ & $0.88(0.08)$ & $0.037^{\mathrm{a}}$ \\
\hline Male probands & 92 & $0.97(0.06)$ & $0.96(0.06)$ & 0.43 \\
\hline Female probands & 58 & $0.89(0.07)$ & $0.92(0.10)$ & 0.14 \\
\hline
\end{tabular}

Data are given as means (SD). Statistical analyses were done by ANOVA.

${ }^{a} p$ value presented is non-parametric calculated using Kruskal-Wallis; the parametric $p$ value is 0.08

Table 3. Results of analyses at the $U C P 3-55 \mathrm{c} \rightarrow \mathrm{t}$ variant for body mass index in two South Indian and one European study group

\begin{tabular}{|c|c|c|c|c|}
\hline & & $U C P 3-55 \mathrm{c} \rightarrow \mathrm{tg}$ & & $p$ value for compari- \\
\hline & $n$ & $\mathrm{cc}$ & $\mathrm{ct} / \mathrm{tt}$ & \\
\hline South Indian trios & & & & \\
\hline Fathers & 85 & $23.9(20.6-27.8)$ & $24.2(21.2-27.6)$ & 0.74 \\
\hline Mothers & 85 & $25.4(21.5-30.0)$ & $25.4(21.6-29.9)$ & 1.0 \\
\hline Male probands & 54 & $25.7(22.3-29.7)$ & $27.0(22.6-32.3)$ & 0.28 \\
\hline Female probands & 31 & $26.4(22.6-30.9)$ & $26.3(21.2-32.5)$ & 0.94 \\
\hline South Indian urban s & & & & \\
\hline Males & 235 & $21.6(18.0-25.9)$ & $21.9(18.6-25.7)$ & 0.57 \\
\hline Females & 220 & $22.5(18.4-27.4)$ & $23.0(18.8-28.1)$ & 0.40 \\
\hline European trios & & & & \\
\hline Fathers & 150 & $27.5(23.5-32.2)$ & $26.4(23.2-30.0)$ & 0.08 \\
\hline Mothers & 150 & $27.1(22.6-32.6)$ & $28.0(23.9-32.8)$ & 0.31 \\
\hline Male probands & 92 & $31.2(25.9-37.4)$ & $29.2(25.1-34.0)$ & 0.11 \\
\hline Female probands & 58 & $34.0(25.9-44.6)$ & $31.7(25.7-39.1)$ & 0.30 \\
\hline
\end{tabular}

Data are given in $\mathrm{kg} / \mathrm{m}^{2}$ as geometric means (SD range). Statistical analyses were undertaken on logarithmically transformed data using ANOVA

$0.88(0.08), p=0.037$ ] but not on parametric analysis $(p=0.08)$. Female probands showed a similar trend but this was not significant under either analysis. Using the total association method (as above), overall association for all trios was borderline significant for WHR $(p=0.06)$. On restricting the analysis to the 58 trios with female probands, as expected, the association with $-55 \mathrm{c} \rightarrow \mathrm{t}$ genotype was stronger $(p=0.0025)$. Again, no relation with WHR was seen in the male family members when analysed by ANOVA (Table 2) and there was no association with BMI (Table 3), age at diagnosis, weight or waist circumference. Applying the total association analysis in the 92 families selected for a male proband, an association emerged, however, between the $-55 \mathrm{c} \rightarrow \mathrm{t}$ polymorphism and BMI $(p=0.02)$. On analysing the European trios using QTDT5 for BMI and WHR, no departures from Mendelian expectation were observed.
Linkage disequilibrium with UCP2 exon 8 site. In the same South Indian cohorts, variation at an insertiondeletion polymorphism within exon 8 of the neighbouring $U C P 2$ gene is associated with raised $\mathrm{BMI}$ [30]. The haplotypic relation between these two variants was therefore explored. In South Indians, the tallele at $U C P 3-55$ was in significant positive disequilibrium with the deletion allele in $U C P 2$ [linkage disequilibrium coefficient (D') $=0.70, p=0.0001)]$. Because it is the UCP2 insertion allele which is associated with increased BMI (but not WHR) in South Indians [30], this pattern of disequilibrium suggests independent associations between $U C P 2$ exon 8 and BMI, and between UCP3 -55 and WHR.

In Europeans, a similar pattern of linkage disequilibrium was observed (in all founder chromosomes, $\mathrm{D}^{\prime}=0.43, p=4 \times 10^{-5}$; in untransmitted chromosomes, D' $=0.37, p=0.005)$. In the European and South Indian families, there was no significant rela- 
tion in mothers (or any other group) between $U C P 2$ exon 8 insertion-deletion genotype and WHR (data not shown). In the European mothers (but not in other European relative groups), the $U C P 2$ exon 8 deletion allele showed, however, a weak association with increased BMI when deletion-homozygous subjects were compared with all others [geometric mean (SD range), $28.4(23.9-33.8) \mathrm{kg} / \mathrm{m}^{2}$, vs $26.7(22.5-31.7) \mathrm{kg} /$ $\left.\mathrm{m}^{2}, p=0.036\right]$. This effect was entirely due to the low BMI of heterozygotes because both homozygote groups had similar BMIs [heterozygotes, 26.3 (22.2-31.3) $\mathrm{kg} / \mathrm{m}^{2}$; homozygous insertion, 28.4 $\left.(24.5-33.0) \mathrm{kg} / \mathrm{m}^{2}\right]$.

\section{Discussion}

The main finding from this study is the association between the $\mathrm{t}$-allele at the $-55 \mathrm{c} \rightarrow \mathrm{t} U C P 3$ polymorphism and increased waist-to-hip ratio in female subjects from two South Indian and one European data set. The $-55 \mathrm{c} \rightarrow \mathrm{t}$ variant represents the fifth $U C P 3$ polymorphism for which associations with obesity or related intermediate traits have been claimed [26, 29,31]. Two of these (Val102Ile) and the exon 6 splice variant are almost entirely restricted to subjects of African origin [29] whereas evidence for the silent Tyr99Tyr polymorphism [26] is of borderline statistical significance after correcting for multiple testing and, if true, presumably reflects linkage disequilibrium with a functional variant elsewhere within $U C P 3$ or a neighbouring gene. Indeed in further analyses of the same French cohorts, this Tyr99Tyr effect seems to reflect an association between tt homozygosity at the $-55 \mathrm{c} \rightarrow \mathrm{t}$ polymorphism and increased BMI [31].

The striking feature of our data is not so much the strength of the association but the consistent limitation to female subjects in three independent data sets and two distinct ethnic groups. Women carrying the t-allele (as heterozygotes or homozygotes) show increased WHR compared with cc homozygotes in all five groups studied (European mothers and probands, South-Indian mothers, probands and urban survey), although the European probands did not approach formal significance. We can only speculate on the biological reasons underlying such sex-restricted effects, but note that the obvious sexual dimorphism in human fat distribution must, of necessity, indicate that regulation of the content and distribution of fat mass differs between men and women.

The physiological importance of UCP3 in human energy balance is controversial [27]. Although several studies have shown that $U C P 3$ has uncoupling activity when expressed in yeast $[12,13]$ or mouse myoblasts [11], the fact that $U C P 3$ expression consistently increases during fasting (i.e. when thermogenesis is decreasing) could indicate a primary physiological role as an effector in the metabolic adaptation to increased fatty acid supply [41-43]. A role in fuel partitioning is supported by the increased respiratory quotient observed in subjects with the exon 6 splice variant [29]. Whether or not the main physiological role of $U C P 3$ lies in regulation of thermogenesis or fuel partitioning, defective $U C P 3$ function would still be expected to lead to progressive weight gain in the absence of compensatory weight-maintaining mechanisms.

Studies of $U C P 3$ expression have also proved hard to interpret, with recent publications variously reporting that $U C P 3 \mathrm{mRNA}$ expression is increased [23], decreased [22] or unchanged [41, 42, 44, 45] in obese compared with control subjects. Thus, although some have interpreted increased mRNA expression as indicative of compensatory $U C P 3$ up-regulation in the face of obesity [23], others have suggested that reduced $U C P 3$ expression contributes to the pathogenesis of obesity [22]. Given our findings, one possible explanation for these discrepant results might be differences in sex between the study cohorts [22, 23].

Association studies, as used here, have two main drawbacks. First, they might detect positive associations that reflect confounding effects of population substructure. Although we cannot exclude this as an explanation of our findings, the consistent relation across two ethnically distinct cohorts (and three data sets) argues against this. The failure to detect evidence for association with WHR in the trios using the Allison QTDT-based method (which circumvents concerns about population stratification) is not especially indicative, given the modest number of female probands (31 South Indian and 58 European).

Second, association studies do not, even if population substructure is excluded, provide precise localisation of the aetiological variant. Thus, the association detected at the $-55 \mathrm{c} \rightarrow \mathrm{t}$ polymorphism could reflect linkage disequilibrium with a functional variant elsewhere in $U C P 3$ (or a nearby gene such as $U C P 2$ ). In previous studies on the same South Indian subjects, an insertion allele at a polymorphism in exon 8 of $U C P 2$ was associated with increased BMI [30]. This raises the possibility that these analyses are detecting the same genetic effect, albeit through different phenotypes (BMI and WHR). Although the orientation of $U C P 2$ and $U C P 3$ is such that they are separated by the entire coding regions of both genes (about $20 \mathrm{~kb}$ ) [46], the two loci are in considerable linkage disequilibrium with the UCP3 $-55 \mathrm{t}$-allele positively associated with the $U C P 2$ exon 8 deletion allele in both ethnic groups. In South Indians, the two susceptibility alleles are themselves in negative linkage disequilibrium and the most likely explanation is that the $U C P 2$ exon 8 insertion-deletion and the $U C P 3-55 \mathrm{c} \rightarrow \mathrm{t}$ SNP have entirely separate associations, with BMI and WHR, respectively. The rela- 
tion between these variants is less easy to disentangle in Europeans, given the weak evidence of an association between the deletion allele and increased BMI. Though it is tempting to dismiss the UCP2 exon 8 / BMI relation in Europeans as a statistical artefact (because heterozygotes have a lower BMI than either homozygote group), it is worth noting that the same ' $V$ '-shape relation has been seen previously at this locus for leptin concentrations in obese European women [30] and sleeping metabolic rate in Pima Indians [28]. Nevertheless, the parsimonious explanation, given the clearer interpretation in the South Indians and the findings that the $U C P 3$ variant influences WHR but not BMI, and the UCP2 polymorphism the reverse, favours distinct effects at the two sites in Europeans as well.

In French subjects, an association has recently been reported between increased BMI and tt homozygosity at this site, evident within both obese and control cohorts (but without any difference in allele frequencies between the two groups) [31]. The QTDT results obtained here offer some support for these findings, although interpretation is complicated when analysed by ANOVA, the South Indian and, since, European groups showed no overall association. If anything, the trend for BMI in Europeans is in the opposite direction. In our cohorts, therefore, any association with BMI lacks the consistency seen for WHR. Unfortunately, no analyses of WHR were reported in the French data [31]. Associations or linkages between the $U C P 3 / U C P 2$ locus and various intermediate traits related to diabetes or obesity have now been reported in South Asians, Pima Indians, Africans and diverse European groups emphasising the importance of this chromosomal region to weight homeostasis [15, 16, 26, 28-31].

According to the original designation of transcription initiation $[6,7]$, the $-55 \mathrm{c} \rightarrow \mathrm{t}$ polymorphism lies in the proximal promoter, immediately adjacent to a putative TATA box. Detailed analysis of the 5' flanking region of $U C P 3$ has, however, recently suggested that the first exon extends a further 581bp upstream than previously thought [47]. This raises questions about the mechanisms whereby the $-55 \mathrm{c} \rightarrow \mathrm{t}$ polymorphism might influence $U C P 3$ function and regulation. Pima Indian subjects homozygous for the c-allele at this site have reduced skeletal muscle $U C P 3$ mRNA expression [48], although, of course, this does not localise the effect to this particular polymorphism. Ultimately, direct comparison of the expression of wildtype and variant $U C P 3$ will be required to assess the functional consequences of genomic variation at this site but it could prove difficult to find a physiologically relevant expression system.

Our studies of the $U C P 3-55 \mathrm{c} \rightarrow \mathrm{t}$ polymorphism in South Indian and European subjects with diabetes and obesity showed no association with diabetes or obesity as such but a replicated association with al- tered fat distribution seen in women from both ethnic groups. Further clinical studies and in vitro functional analyses are required to define the precise contribution of this variant to human physiology and pathology, but the data provide additional support for the hypothesis that defects in UCP3 function contribute to the development of obesity and related conditions.

Acknowledgements. The European Trios collection was supported by the British Diabetic Association through the Warren Bequest and the South-Indian collection by the Wellcome Trust. The laboratory work was funded by the British Diabetic Association and United Kingdom Medical Research Council. We thank M. Murphy and S. Howell for their contribution to establishing the Warren Trios collection; F. Bottazzo and R. Foxon for the anti-GAD assays; D. Curtis and G. Abecasis for statistical advice; R. Turner, J. Levy and M. Sampson and the many research nurses, diabetes physicians and family members who contributed to the family collections.

\section{References}

1. Ravussin E, Bogardus C (1992) A brief overview of human energy metabolism and its relationship to essential obesity. Am J Clin Nutr 55: 242S-245S

2. Ravussin E, Lillioja S, Knowler WC et al. (1988) Reduced rate of energy expenditure as a risk factor for body-weight gain. N Engl J Med 318: 467-472

3. Robinson S, Chan SP, Spacey S, Anyaoku V, Johnston DG, Franks S (1992) Postprandial thermogenesis is reduced in polycystic ovary syndrome and is associated with increased insulin resistance. Clin Endocrinol (Oxf) 36: 537-543

4. Robinson S, Niththyananthan R, Anyaoku V, Elkeles RS, Beard RW, Johnston DG (1994) Reduced postprandial energy expenditure in women predisposed to type 2 diabetes. Diabet Med 11: 545-550

5. Fleury C, Neverova M, Collins S et al. (1997) Uncoupling protein-2: a novel gene linked to obesity and hyperinsulinemia. Nat Genet 15: 269-272

6. Vidal-Puig A, Solanes G, Grujic D, Flier JS, Lowell BB (1997) UCP3: an uncoupling protein homologue expressed preferentially and abundantly in skeletal muscle and brown adipose tissue. Biochem Biophys Res Commun 235: 79-82

7. Solanes G, Vidal-Puig A, Grujic D, Flier JS, Lowell BB (1997) The human uncoupling protein-3 gene. Genomic structure, chromosomal localization, and genetic basis for short and long form transcripts. J Biol Chem 272: 25433-25436

8. Boss O, Samec S, Paoloni-Giacobino A et al. (1997) Uncoupling protein-3: a new member of the mitochondrial carrier family with tissue-specific expression. FEBS Lett 408: $39-42$

9. Kopecky J, Clarke G, Enerbäck S, Spiegelman B, Kozak LP (1995) Expression of the mitochondrial uncoupling protein gene from the aP2 gene promoter prevents genetic obesity. J Clin Invest 96: 2914-2923

10. Kopecky J, Hodny Z, Rossmeisl M, Syrovy I, Kozak LP (1996) Reduction of dietary obesity in aP2-Ucp transgenic mice: physiology and adipose tissue distribution. Am J Physiol 270: E768-E775

11. Boss O, Samec S, Kuhne F et al. (1998) Uncoupling protein-3 expression in rodent skeletal muscle is modulated by food intake but not by changes in environmental temperature. J Biol Chem 273: 5-8 
12. Liu Q, Bai C, Chen F et al. (1998) Uncoupling protein-3: a muscle-specific gene upregulated by leptin in ob/ob mice. Gene 207: 1-7

13. Gong DW, He Y, Karas M, Reitman M (1997) Uncoupling protein-3 is a mediator of thermogenesis regulated by thyroid hormone, beta3-adrenergic agonists, and leptin. J Biol Chem 272: 24129-24132

14. Zurlo F, Larson K, Bogardus C, Ravussin E (1990) Skeletal muscle metabolism is a major determinant of resting energy expenditure. J Clin Invest 86: 1423-1427

15. Bouchard C, Perusse L, Chagnon YC, Warden C, Ricquier D (1997) Linkage between markers in the vicinity of the uncoupling protein 2 gene and resting metabolic rate in humans. Hum Mol Genet 6: 1887-1889

16. Pratley RE, Thompson DB, Bogardus C (1998) An autosomal gene scan for loci linked to prediabetic phenotypes in Pima Indians. J Clin Invest 101: 1757-1764

17. Warden CH, Fisler JS, Pace MJ, Svenson KL, Lusis AJ (1993) Coincidence of genetic loci for plasma cholesterol levels and obesity in a multifactorial mouse model. J Clin Invest 92: 773-779

18. Seldin MF, Mott D, Bhat D et al. (1994) Glycogen synthase: a putative locus for diet-induced hyperglycemia. J Clin Invest 94: 269-276

19. Warden CH, Fisler JS, Shoemaker SM et al. (1995) Identification of four chromosomal loci determining obesity in a multifactorial mouse model. J Clin Invest 95: 1545-1552

20. Taylor BA, Phillips SJ (1996) Detection of obesity QTLs on mouse chromosomes 1 and 7 by selective DNA pooling. Genomics 34: 389-398

21. Kaisaki PJ, Woon PY, Wallis RH, Monaco AP, Lathrop M, Gauguier D (1998) Localization of tub and uncoupling proteins (Ucp) 2 and 3 to a region of rat Chromosome 1 linked to glucose intolerance and adiposity in the Goto-Kakizaki (GK) Type 2 diabetic rat. Mamm Genome 9: 910-912

22. Schrauwen P, Xia J, Bogardus C, Pratley RE, Ravussin E (1999) Skeletal muscle uncoupling protein 3 expression is a determinant of energy expenditure in Pima Indians. Diabetes 48: 146-149

23. Bao S, Kennedy A, Wojciechowski B, Wallace P, Ganaway E, Garvey WT (1998) Expression of mRNAs encoding uncoupling proteins in human skeletal muscle: effects of obesity and diabetes. Diabetes 47: 1935-1940

24. Krook A, Digby J, O'Rahilly S, Zierath JR, Wallberg-Henriksson H (1998) Uncoupling protein 3 is reduced in skeletal muscle of NIDDM patients. Diabetes 47: 1528-1531

25. Urhammer SA, Dalgaard LT, Sorensen TI et al. (1998) Organisation of the coding exons and mutational screening of the uncoupling protein 3 gene in subjects with juvenileonset obesity. Diabetologia 41: 241-244

26. Otabe S, Clement K, Dubois S et al. (1999) Mutation screening and association studies of the human uncoupling protein 3 gene in normoglycemic and diabetic morbidly obese patients. Diabetes 48: 206-208

27. Chung WK, Luke A, Cooper RS et al. (1999) Genetic and physiologic analysis of the role of uncoupling protein 3 in human energy homeostasis. Diabetes 48: 1890-1895

28. Walder K, Norman RA, Hanson RL (1998) Association between uncoupling protein polymorphisms (UCP2-UCP3) and energy metabolism/obesity in Pima indians. Hum Mol Genet 7: 1431-1435

29. Argyropoulos G, Brown AM, Willi SM et al. (1998) Effects of mutations in the human uncoupling protein 3 gene on the respiratory quotient and fat oxidation in severe obesity and type 2 diabetes. J Clin Invest 102: 1345-1351
30. Cassell PG, Neverova M, Janmohamed S et al. (1999) An uncoupling protein 2 gene variant is associated with a raised body mass index but not Type II diabetes. Diabetologia 42: 688-692

31. Otabe S, Clement K, Dina C et al. (2000) A genetic variation in the 5' flanking region of the UCP3 gene is associated with body mass index in humans in interaction with physical activity. Diabetologia 43: 245-249

32. McCarthy MI, Hitman GA, Shields DC et al. (1994) Family studies of non-insulin-dependent diabetes mellitus in South Indians. Diabetologia 37: 1221-1230

33. McCarthy M, Cassell P, Tran T et al. (1996) Evaluation of the importance of maternal history of diabetes and of mitochondrial variation in the development of NIDDM. Diabet Med 13: 420-428

34. Ramachandran A, Snehalatha C, Dharmaraj D, Viswanathan M (1992) Prevalence of glucose intolerance in Asian Indians. Urban-rural difference and significance of upper body adiposity. Diabetes Care 15: 1348-1355

35. Frayling TM, Walker M, McCarthy MI et al. (1999) Parentoffspring trios: a resource to facilitate the identification of type 2 diabetes genes. Diabetes 48: 2475-2479

36. Sham PC, Curtis D (1995) An extended transmission/disequilibrium test (TDT) for multi-allele marker loci. Ann Hum Genet 59: 323-336

37. Allison DB (1997) Transmission-disequilibrium tests for quantitative traits. Am J Hum Genet 60: 676-690

38. Abecasis GR, Cardon LR, Cookson WO (2000) A general test of association for quantitative traits in nuclear families. Am J Hum Genet 66: 279-292

39. Clayton D (1999) A generalization of the transmission/disequilibrium test for uncertain-haplotype transmission. Am J Hum Genet 65: 1170-1177

40. Xie X, Ott J (1993) Testing linkage disequilibrium between a disease gene and marker loci. Am J Hum Genet 53 [Suppl 3]: 1107

41. Millet L, Vidal H, Andreelli F et al. (1997) Increased uncoupling protein-2 and -3 mRNA expression during fasting in obese and lean humans. J Clin Invest 100: 2665-2670

42. Boss O, Bobbioni-Harsch E, Assimacopoulos-Jeannet F et al. (1998) Uncoupling protein-3 expression in skeletal muscle and free fatty acids in obesity. Lancet 351: 1933

43. Weigle DS, Selfridge LE, Schwartz MW et al. (1998) Elevated free fatty acids induce uncoupling protein 3 expression in muscle: a potential explanation for the effect of fasting. Diabetes 47: 298-302

44. Millet L, Vidal H, Larrouy D, Andreelli F, Laville M, Langin D (1998) mRNA expression of the long and short forms of uncoupling protein-3 in obese and lean humans. Diabetologia 41: 829-832

45. Nordfors L, Hoffstedt J, Nyberg B et al. (1998) Reduced gene expression of UCP2 but not UCP3 in skeletal muscle of human obese subjects. Diabetologia 41: 935-939

46. Pecqueur C, Cassard-Doulcier AM, Raimbault S et al. (1999) Functional organization of the human uncoupling protein-2 gene, and juxtaposition to the uncoupling protein-3 gene. Biochem Biophys Res Commun 255: 40-46

47. Acin A, Rodriguez M, Rique H, Canet E, Boutin JA, Galizzi JP (1999) Cloning and characterization of the 5' flanking region of the human uncoupling protein 3 (UCP3) gene. Biochem Biophys Res Commun 258: 278-283

48. Schrauwen P, Xia J, Walder K, Snitker S, Ravussin E (1999) A novel polymorphism in the proximal UCP3 promoter region: effect on skeletal muscle UCP3 mRNA expression and obesity in male non-diabetic Pima Indians. Int J Obes Relat Metab Disord 23: 1242-1245 